\title{
Stochastic spatial disaggregation of extreme precipitation to validate a regional climate model and to evaluate climate change impacts over a small watershed
}

\author{
P. Gagnon ${ }^{1, *}$ and A. N. Rousseau ${ }^{1}$ \\ ${ }^{1}$ Institut National de la Recherche Scientifique, Centre eau, terre et environnement, Université du Québec, \\ 490 rue de la Couronne, Québec city, PQ, G1K 9A9, Canada \\ *now at: Agriculture and Agri-Food Canada, 2560 Hochelaga Blvd., Québec city, PQ, G1V 2J3, Canada
}

Correspondence to: P. Gagnon (patrickgagnon82@gmail.com)

Received: 30 May 2013 - Published in Hydrol. Earth Syst. Sci. Discuss.: 26 June 2013

Revised: 5 March 2014 - Accepted: 20 March 2014 - Published: 9 May 2014

\begin{abstract}
Regional climate models (RCMs) are valuable tools to evaluate impacts of climate change (CC) at regional scale. However, as the size of the area of interest decreases, the ability of a RCM to simulate extreme precipitation events decreases due to the spatial resolution. Thus, it is difficult to evaluate whether a RCM bias on localized extreme precipitation is caused by the spatial resolution or by a misrepresentation of the physical processes in the model. Thereby, it is difficult to trust the CC impact projections for localized extreme precipitation. Stochastic spatial disaggregation models can bring the RCM precipitation data at a finer scale and reduce the bias caused by spatial resolution. In addition, disaggregation models can generate an ensemble of outputs, producing an interval of possible values instead of a unique discrete value.

The objective of this work is to evaluate whether a stochastic spatial disaggregation model applied on annual maximum daily precipitation (i) enables the validation of a RCM for a period of reference, and (ii) modifies the evaluation of $\mathrm{CC}$ impacts over a small area. Three simulations of the Canadian RCM (CRCM) covering the period 1961-2099 are used over a small watershed $\left(130 \mathrm{~km}^{2}\right)$ located in southern Québec, Canada. The disaggregation model applied is based on Gibbs sampling and accounts for physical properties of the event (wind speed, wind direction, and convective available potential energy - CAPE), leading to realistic spatial distributions of precipitation. The results indicate that disaggregation has a significant impact on the validation. However, it does not provide a precise estimate of the simulation bias because
\end{abstract}

of the difference in resolution between disaggregated values $(4 \mathrm{~km})$ and observations, and because of the underestimation of the spatial variability by the disaggregation model for the most convective events. Nevertheless, disaggregation illustrates that the simulations used mostly overestimated annual maximum precipitation depth in the study area during the reference period. Also, disaggregation slightly increases the signal of CC compared to the RCM raw simulations, highlighting the importance of spatial resolution in $\mathrm{CC}$ impact evaluation of extreme events.

\section{Introduction}

Extreme precipitation events may cause disasters, such as flooding, dam failure, soil erosion, and landslide, which may have substantial social, economic and environmental impacts. In many cases, as for instance dam building or development of new habitable zone, a good knowledge of the occurrence of extreme events is required to properly evaluate the risk (i.e., the expected cost of damage caused by extreme precipitation). In a context of climate change (CC), past impact studies made with a stationary climate assumption must be reconsidered.

There is a consensus in the scientific community about the existence of CC (IPCC, 2007). While an increase of the mean global temperature is expected from climate model projections (IPCC, 2007), there is uncertainty associated with precipitation change. The effect of $\mathrm{CC}$ on precipitation 
varies spatially and temporally. With regards to extreme precipitation, Sunyer et al. (2012) used four regional climate model (RCM) projections in Denmark and obtained discordant results for 20- and 100-year return periods. Fowler and Ekström (2009) found an increase in extreme precipitation intensities projected by climate models in United Kingdom, but the results varied between regions and the variability increased with the return period. Using different projections from a single climate model, Mladjic et al. (2011) detected significant increases in extreme precipitation depths in 7 out of 10 climatic regions in Canada.

Because of this uncertainty, a robust CC impact evaluation for a given area must include several future climate projections, coming from various climate models and greenhouse gas (GHG) emission scenarios. A valuable criterion in the selection of a climate model is the ability to simulate the recent past in the study area. This performance is evaluated through a comparison between observed and simulated values of the variable of interest.

For extreme events, the spatial resolution becomes very important. This implies that, for a proper validation of a simulation, the spatial resolutions of observed and simulated values must be similar. When the area of interest is small (e.g., an area smaller than a climate model grid box within which observations come from a single station), the raw simulated values must be downscaled to a finer scale. In this case, the validation of a simulation depends on the downscaling technique. Therefore, it is primordial that the downscaling technique be realistic and robust to enable a precise evaluation of the simulation bias.

Without an adequate downscaling technique, one can assume that the CC impact in the area is the same as that in the grid box. However, this assumption does not stand if the types of events, affecting the spatial distribution of precipitation, change in the future (e.g., if there are more convective events due to an increase in temperature). A popular method is the use of a single multiplicative factor that accounts for the change in the mean (Sunyer et al., 2012). However, it is not suitable for extreme precipitation since for a given location, the projected mean annual precipitation may decrease while the number and magnitude of high precipitation events might increase (Amengual et al., 2012). Also, the CC signal may be stronger for extreme than for moderate events (Hanel and Buishand, 2012).

There exist two approaches that bring a simulated field to a finer spatial scale. The first approach is to run a climate model nested in a spatial domain smaller than the original simulation. The smaller spatial domain permits the refining of the spatial resolution of the grid for the same computational requirements. This approach is often referred to as $d y$ namical downscaling (Boé et al., 2007). The most common example is the use of a RCM to refine the resolution of global climate models (GCMs). It is also possible to run a RCM two or more times in domains nested one inside the other (Yu et al., 2002). Dynamical downscaling produces physically sound data, but it in the end requires intensive computational resources.

The second approach is to apply a stochastic model, for which each climate model grid box is subdivided into several elements (pixels) whose precipitation depth is a random variable depending on neighboring pixels and possibly other relevant variables. This kind of model is often referred to as a disaggregation model (e.g., Mackay et al., 2001). Disaggregation models may be applied after dynamical downscaling. The most popular technique used by the existing disaggregation models is the multiplicative cascade (see e.g., Over and Gupta, 1996; Harris and Foufoula-Georgiou, 2001; and Sharma et al., 2007). The advantages of this technique are its relative rapidity and simplicity of use, but it often produces precipitation fields with unrealistic spatial structures, with visible discontinuities (Lovejoy and Schertzer, 2010). In order to account for the type of precipitation event, Perica and Foufoula-Georgiou (1996) developed a disaggregation model based on wavelet transform with parameters related to the convective available potential energy (CAPE). Gagnon (2012) recently proposed a stochastic disaggregation model accounting for CAPE, wind speed and wind direction. To our knowledge, there is no other spatial disaggregation model using a stochastic algorithm and the physical properties CAPE, wind speed and wind direction as covariates. This approach provides a way to produce spatially coherent fields, which is the main challenge for spatial disaggregation models. This model has not been applied yet to downscale precipitation from a climate model projection.

There are two objectives here. First, we want to determine whether the disaggregation model proposed by Gagnon (2012) enables the validation of the annual maximum daily precipitation (AMDP) simulated by a RCM over a small area when only a single observation point is available. Second, for the same small area and using the same disaggregation model, we want to quantify the difference, if any, in the evaluation of the CC impact on AMDP between raw and downscaled RCM simulations. The general motivation behind these two objectives is to provide reliable information to policymakers, who must manage the risk associated with CC projection for extreme precipitation over a small area.

The next section introduces the study area along with a description of the observed and simulated data. Section 3 presents the disaggregation model used in this study (Gagnon, 2012; Gagnon et al., 2012). Section 4 describes the methodology applied to evaluate the capability of the disaggregation model to validate a RCM simulation and to enhance the CC impact evaluation. Section 5 shows the results of the validation and the $\mathrm{CC}$ evaluation exercises. A conclusion (Sect. 6) completes the paper. 


\section{Case study}

\subsection{Study area}

The study area is a $132 \mathrm{~km}^{2}$ sub-watershed of the Yamaska River, located south of the St. Lawrence River, Québec, Canada. The outlet of this sub-watershed is the Choinière dam (Fig. 1). It is one of the several small dams located in the Yamaska River watershed, but is a high-risk dam with respect to the city of Ste. Hyacinthe, located downstream. A study of the impact of $\mathrm{CC}$ on the probable maximum flood (PMF) has already been done for this sub-watershed (Rousseau et al., 2012), but no downscaling technique was used.

The climate is continental wet, characterized by large variations of temperature and no dry season. The mean annual precipitation of the Yamaska River watershed is about $1200 \mathrm{~mm}$, of which more than $900 \mathrm{~mm}$ is liquid (Rousseau et al., 2012). Most of winter precipitation falls as snow, while summer precipitation can come from either large-scale or convective events. The Choinière dam watershed, as most of the Yamaska River watershed, is located in the St. Lawrence Lowlands, characterized by a flat topography and arable soils. The extreme southeast or upstream region of the area is covered by the Appalachian Mountains.

\subsection{Observed data}

Daily observed precipitation data come from the Québec Centre of Water Expertise (Centre d'Expertise Hydrique du Québec, CEHQ) meteorological grid (CEHQ, 2012). This grid has a $0.1^{\circ}$ resolution (approximately $10 \mathrm{~km}$ ) and the data at each grid node are generated by kriging interpolation of the surrounding weather station data (CEHQ, 2012). The observed daily rainfall data retained for the validation exercise come from the only grid node covering the Choinière watershed $\left(45.4^{\circ} \mathrm{N}, 72.5^{\circ} \mathrm{W}\right.$; star, Fig. 1$)$. The data set covers the 1961-2000 period and only the data from May to October are analyzed. November to April data are not used in this work, as we focus on liquid precipitation. In addition to precipitation, daily minimum and maximum temperatures are also available on the CEHQ grid, but are not used in the present study.

As the observed data come from interpolation, the exact spatial resolution of the observations is unknown, affecting the comparison between raw simulated values and those produced by the disaggregation model. However, resolution of the weather station network is relatively high in this area, improving confidence in the interpolation results.

\subsection{Simulated data}

The simulated data come from three simulations of the Canadian RCM version 4.2.3 (CRCM, Caya and Laprise, 1999; de Elía and Côté, 2010; Paquin, 2010), referred as afx, agr and $a h a$. The CRCM has a three-dimensional grid with horizontal resolution of about $45 \mathrm{~km}$ (true at $60^{\circ} \mathrm{N}$ ). The three

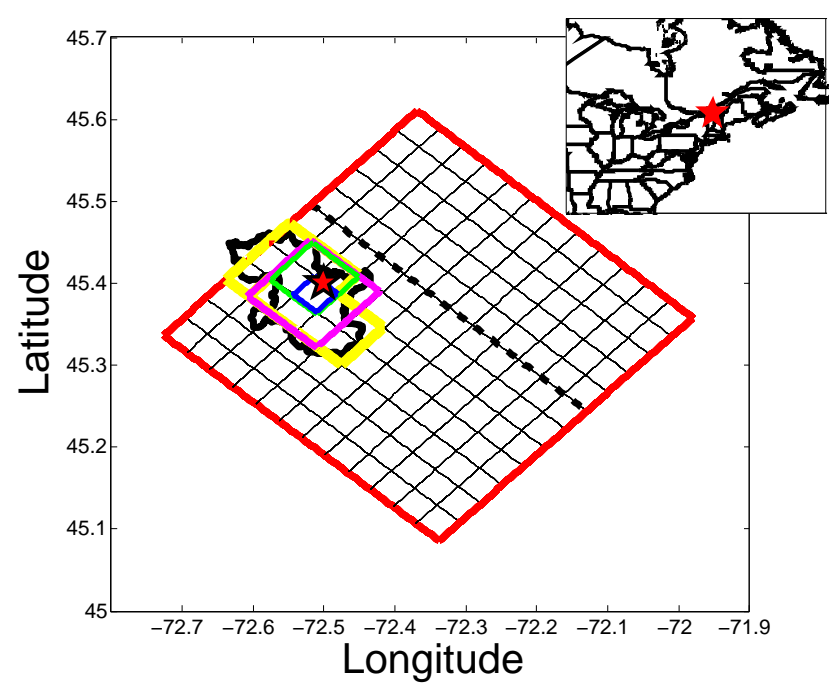

Fig. 1. Study area: Choinière watershed $\left(132 \mathrm{~km}^{2}\right)$, CEHQ grid node (star), CRCM tile (red), $12 \mathrm{~km}$ (purple), $8 \mathrm{~km}$ (green) and $4 \mathrm{~km}$ (blue) pixels. The pixels covering the watershed are in yellow. The dashed line is the west-east axis of the CRCM grid.

simulations analyzed cover a domain of $111 \times 87$ grid nodes centered over the province of Québec, Canada. The runs were driven by atmospheric fields taken from members 4 and 5 of the third generation of the Canadian Coupled Global Climate Model (CGCM3; Flato et al., 2000; Flato and Boer, 2001; Scinocca et al., 2008) for $a f x$ and $a g r$, respectively, and from member 1 of the German Coupled Global Climate Model ECHAM5 (Junglaus et al., 2006) for aha. The data cover the 1961-2099 period and both global and regional simulations were performed using the IPCC SRES A2 GHG and aerosol projected evolution (Nakicenovic and Swart, 2000). Precipitation data from 1961 to 2000 are used for the comparison between observed and simulated data, while the 1961-2099 period is used for the CC impact assessment. As previously mentioned, only data from May to October are retained for the analyses.

In addition to precipitation, daily mean wind speed and wind direction at the $700 \mathrm{hPa}$ level as well as the daily mean CAPE simulated fields are required to run the disaggregation model (Sect. 3). Five by five CRCM tiles, covering the Yamaska watershed, are disaggregated, but the outcomes of only one tile (tile $(3,4)$ of the $5 \times 5$ computational domain), covering the studied watershed, are retained for the analyses (red tile, Fig. 1). The three simulations used were the only RCM simulations available for our pilot study. The authors are aware that a CC impact assessment study cannot be made with only three simulations coming from only one RCM. The aim of this work is to evaluate a methodology; the results of this work must not be taken as a complete CC impact assessment study. 


\section{Disaggregation model}

The disaggregation model used is a stochastic model that enables the use of information produced using a $45 \mathrm{~km}$ resolution field to generate realistic fields at a finer spatial scale (from 4 to $23 \mathrm{~km}$ resolution). The model is described in detail in Gagnon (2012) and a slightly different anterior version of the model is also presented in Gagnon et al. (2012). This section describes the main features of the model.

Since observed and simulated data are both available on a daily time step, temporal disaggregation of precipitation was not considered. The authors are aware that for some hydrological applications on small watersheds, a finer time step (e.g., hourly) would be required. The actual version of the disaggregation model described herein does not perform temporal disaggregation.

\subsection{Mathematical framework}

Let $R_{i, j}$ be the precipitation on pixel $(i, j)$ for a given day. In this study, the spatial resolution of the pixel may be 4,8 or $12 \mathrm{~km}$. The eight surrounding pixels are used to define the mean precipitation in the four directions: $A_{/}=\frac{R_{i-1, j-1}+R_{i+1, j+1}}{2}, A_{\mid}=\frac{R_{i-1, j}+R_{i+1, j}}{2}$, $A_{\backslash}=\frac{R_{i-1, j+1}+R_{i+1, j-1}}{2}$, and $A_{-}=\frac{R_{i, j-1}+R_{i, j+1}}{2}$. It is assumed that $R_{i, j}$ has a lognormal distribution with the expected value $\mu$ given by (Gagnon, 2012; Gagnon et al., 2012)

$$
\begin{aligned}
\mu & =\bar{A}+\beta_{d}\left(\frac{A_{\downarrow}+A_{-}}{2}-\frac{A_{\backslash}+A_{/}}{2}\right) \\
& +\beta_{\times}\left(A_{/}-A_{\backslash}\right)+\beta_{+}\left(A_{\downarrow}-A_{-}\right),
\end{aligned}
$$

where $\bar{A}$ is the mean precipitation of the eight surrounding pixels and $\beta_{d}, \beta_{x}$ and $\beta_{+}$are parameters to estimate. The parameter $\beta_{d}$ accounts for the distance of the surrounding pixels while the two others account for anisotropy. Equation (1) is the expected value equation of Gagnon et al. (2012). In Gagnon (2012), this equation is modified by expressing the two anisotropy parameters as functions of daily mean wind speed $\left(V ; \mathrm{m} \mathrm{s}^{-1}\right)$ and wind direction $(W$; degree $)$ at $700 \mathrm{hPa}$ :

$\beta_{\times}=\beta_{v} V \cos \left(2\left(W-45^{\circ}\right)\right)$

and

$\beta_{+}=\beta_{v} V \cos \left(2\left(W-90^{\circ}\right)\right)$.

Anisotropy is thereby accounted for by one parameter, $\beta_{v}$, instead of two. In the present study, $V$ and $W$ at $700 \mathrm{hPa}$ come from CRCM simulations and the reference axis for $W$ is the west-east axis of the CRCM grid (dashed line; Fig. 1).

The standard deviation $\sigma$ is assumed to increase with the expected value and to linearly increase with the daily mean convective available potential energy (CAPE) value $\left(\mathrm{J} \mathrm{kg}^{-1}\right)$ of the CRCM tile $(C)$ :

$\sigma=\left(\theta_{0}+\theta_{1} C\right) \mu^{\theta_{2}}$,

where $\theta_{0}, \theta_{1}$ and $\theta_{2}$ are parameters to estimate.
The parameter values were estimated for the southeast region of the US since there was a high amount of precipitation data at a high spatial resolution. A total of $92163.8 \mathrm{~km}$ pixels, covering about $130000 \mathrm{~km}^{2}$, from the National Centers for Environmental Prediction (NCEP) Stage IV project (Lin and Mitchell, 2005) were used for the calibration. More than 5 million wet pixel-days were available during the 4-year calibration period (2002-2005; Gagnon, 2012). The Stage IV data set covers only a small part of the southernmost region of Québec (near the study area) with $4.4 \mathrm{~km}$ pixels. Parameter values estimated for about 60000 wet pixel-days in summer in that region of Québec were similar to those estimated for southeastern United States (Gagnon, 2012). In this work, the parameter values from southeastern United States are used due to the larger calibration data set.

\subsection{Algorithm}

Section 3.1 provided the statistical distribution of the daily precipitation at a pixel when precipitation depths of the neighboring pixels are known. However, since only precipitation of the RCM tile is known, a stochastic algorithm, based on Gibbs sampling (Geman and Geman, 1984; Roberts and Smith, 1994), is used to produce finer-scale precipitation fields using the aforementioned mathematical framework (Sect. 3.1).

Recall that $5 \times 5$ CRCM tiles are disaggregated, but only the values of the tile $(3,4)$, covering the Choinière watershed, are used. The disaggregation model needs a buffer zone around the area of interest to produce realistic precipitation fields (Gagnon, 2012). For each $45 \mathrm{~km}$ CRCM tile, the disaggregation will produce $n \times n$ pixels per tile $(n=12,6$ and 4 for pixel sizes of 4,8 and $12 \mathrm{~km}$, respectively). The algorithm proceeds as follows for each day of each CRCM simulation:

1. First, set the precipitation of each pixel equal to the precipitation of the coarser CRCM tile. Thus, all pixels within a CRCM tile have the same amount of precipitation.

2. Generate a new value for pixel $(1,1)$ according to the distribution set in Sect. 3.1. If it is the first iteration, the expected value is equal to the precipitation of the coarser CRCM tile.

3. Generate new values for the other pixels, one at a time, according to the distribution set in Sect. 3.1. The expected value and the standard deviation for a pixel are updated according to the new precipitation values of the neighboring pixels. When all pixels have been updated once, one iteration is completed.

4. Repeat steps (b) and (c) 300 times to annihilate the impact of the initial condition (step a). The first disaggregated field is retained. 
5. Repeat steps (b) and (c) 100 times to annihilate the autocorrelation with the last retained disaggregated field. Then, a second disaggregated field is retained.

6. Repeat step (e) as many times as desired to retain several disaggregated fields. In this work, 100 disaggregated fields are retained for each day of each simulation.

Note that for pixels located on a boundary of the disaggregation domain, Eq. (1) is slightly modified to account for the fact that the pixel has less than eight neighbors (Gagnon, 2012). Also note that this version of the disaggregation model does not explicitly account for topography. Gagnon (2012) showed that it is not necessary in areas with no abrupt variations in elevations (like the study area), since the impact of topography is indirectly accounted for in the CRCM precipitation fields. For a version of the model adapted for highly variable topography, the reader is referred to Gagnon et al. (2013).

\section{Methods}

\subsection{Validation of the simulations (1961-2000)}

Climate simulation bias may be caused by a misrepresentation of the physical processes by the climate model (physical bias) and/or by the difference between the spatial resolution of the model and that of the observation (spatial resolution bias). In this work, the disaggregation model is applied to eliminate, or at least reduce the spatial resolution bias. This would allow a proper evaluation of the physical bias of the climate simulation in the area of interest.

RCM simulated data driven by a GCM have no simultaneity with observations. Thus, the distributions of simulated and observed AMDP must be compared without correlation measures. Instead, the cumulative observed and simulated distributions of the 40 AMDPs (May to October, 19612000) are compared. The 40 maximum observed values come from the unique CEHQ grid node covering the watershed (Sect. 2.2; star, Fig. 1).

The annual maximum simulated series $\left(Y_{45 \mathrm{~km}, t} ; t \in\right.$ $\{1961, \ldots, 2000\}$ ) comes from the CRCM grid node covering the watershed (raw values; red tile, Fig. 1) and from the results of the disaggregation model for the $4 \mathrm{~km}$ pixel covering the CEHQ grid node (disaggregated values; blue pixel, Fig. 1). There are 40 raw values (1961 to 2000) and 100 series of 40 disaggregated values. Formally, let $Y_{4 \mathrm{~km}, t, d}^{(k)}$ be the precipitation on the $4 \mathrm{~km}$ pixel covering the CEHQ grid node (blue pixel, Fig. 1) for the $k$ th retained disaggregated field ( $k=\{1, \ldots, 100\}$; Sect. 3.2) of day $d$ of the year $t$. The maximum daily precipitation for year $t$ and disaggregated field $k$, $Y_{4 \mathrm{~km}, t}^{(k)}$, is given by

$Y_{4 \mathrm{~km}, t}^{(k)}=\underset{d \in\{\text { May, }, . ., \text { October }\}}{\max }\left(Y_{4 \mathrm{~km}, t, d}^{(k)}\right)$.
The Mann-Kendall test (Mann, 1945; Kendall, 1975) did not detect any trend for the observed, raw simulation, and for most of the disaggregated series for the 1961-2000 period. Thus, it can be assumed that the 40 values of each series come from the same distribution.

Let $X(p)$ be the $p$ th percentile of the observed AMDP distribution for the reference period. For conciseness, let $X \equiv X(p)$. In the same manner, let $Y_{45 \mathrm{~km}}$ and $Y_{4 \mathrm{~km}}^{*}=\frac{1}{100} \sum_{k=1}^{100} Y_{4 \mathrm{~km}}^{(k)}(p)$ be the $p$ th percentile of the AMDP for the raw simulation and for the mean disaggregated series, respectively, for the same reference period. Also, let $T$ be the true (unknown) $p$ th percentile of the AMDP values at the CEHQ grid node scale (i.e., $(X-T)=$ measurement error). The difference between $Y_{45 \mathrm{~km}}$ (raw simulated value) and $T$ ("target" value) can be written as follows:

$$
\left(Y_{45 \mathrm{~km}}-T\right)=\left(Y_{45 \mathrm{~km}}-Y_{4 \mathrm{~km}}^{*}\right)+\left(Y_{4 \mathrm{~km}}^{*}-X\right)+(X-T) .
$$

The idea is to estimate each term according to percentile $p$. The term $\left(Y_{45 \mathrm{~km}}-Y_{4 \mathrm{~km}}^{*}\right)$ is the impact of the disaggregation and can be estimated from the disaggregated and raw simulated data. This term accounts for most of the spatial resolution bias. The difference between the disaggregated and observed values $\left(Y_{4 \mathrm{~km}}^{*}-X\right)$ can also be estimated from the data. However, this latter term contains three sources of errors: (i) the CRCM simulation bias (physical bias), (ii) the disaggregation model bias and (iii) the difference in resolution between the $4 \mathrm{~km}$ pixel and the observation. The purpose of the validation exercise is to evaluate (i); (ii) and (iii) can be seen as noise. For point (ii), Gagnon (2012) showed, for convective events, that the disaggregation can underestimate the $4 \mathrm{~km}$ daily precipitation by up to $50 \%$ at worst. Since the calibration of the disaggregation model was performed using 4 years only, the bias cannot be expressed as a function of $p$ over 40 years. The exact value of point (iii) is unknown, but its order of magnitude can be roughly estimated from the analyses of the disaggregation results at 12,8 and $4 \mathrm{~km}$ (purple, green, and blue pixels of Fig. 1, respectively). The last term $(X-T)$ is the difference between the observed and the real value. It is caused by measurement errors. Measurement errors are more important for solid than for liquid precipitation (Goodison et al., 1998; Yang et al., 1999; Fortin et al., 2008). As only precipitation from May to October are analyzed, this term is assumed negligible compared to other terms and is not considered here. It is thereby assumed that the left-hand side of Eq. (6) $\left(Y_{45 \mathrm{~km}}-T\right)$ is approximately equal to $\left(Y_{45 \mathrm{~km}}-X\right)$.

To estimate the relative importance for a given $p$ of the aforementioned effects, for each climate simulation, each effect will be expressed with respect to the range of the distribution of the $4 \mathrm{~km}$ disaggregated values. 


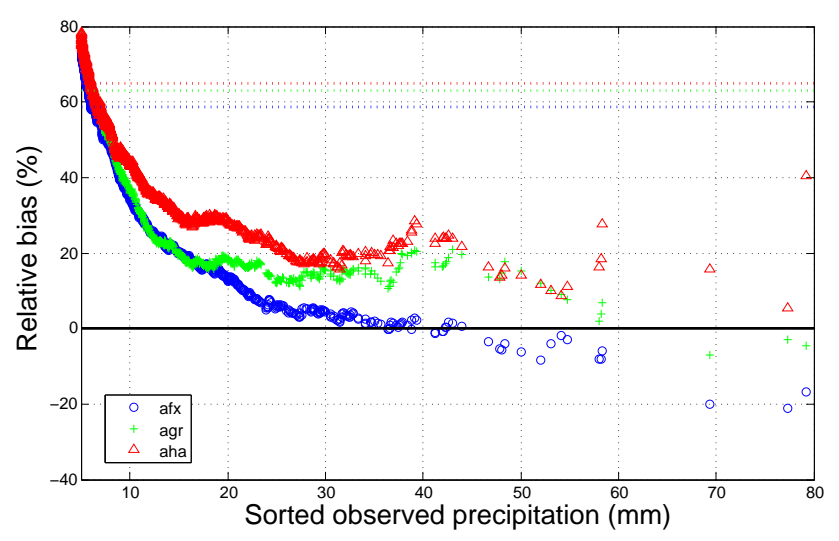

Fig. 2. Relative difference (\%) between simulated and observed distributions of daily precipitation for the reference period (May to October, 1961-2000). The dotted lines are the mean relative bias for the three simulations over the whole reference period.

\subsection{Impact of climate change (1961-2099)}

For the evaluation of the impact of $\mathrm{CC}$ on the watershed, the raw simulation and the 100 disaggregated series of AMDP (May to October, 1961-2099) are analyzed for each CRCM simulation. Contrary to the validation exercise (Sect. 4.1), the disaggregated values come from the mean of the values of the 13 pixels covering the Choinière watershed (yellow pixels, Fig. 1).

The CC impacts are compared in two manners. The first comparison is on the magnitude and on the statistical significance of the long-term trend. The statistical significance is evaluated from the non-parametric Mann-Kendall test (Mann, 1945; Kendall, 1975) and the magnitude is evaluated assuming a linear relationship between annual maximum and time (year). Formally, the regression equation for a given raw simulation (afx, agr or aha) and for any of the $k$ disaggregated series $(k=\{1, \ldots, 100\})$ are given by

$Y_{45 \mathrm{~km}, t}=\beta_{0,45 \mathrm{~km}}+\beta_{1,45 \mathrm{~km}} t$

and

$Y_{4 \mathrm{~km}, t}^{(k)}=\beta_{0,4 \mathrm{~km}}^{(k)}+\beta_{1,4 \mathrm{~km}}^{(k)} t$,

respectively, where $t$ is the year. The estimated $\beta$ s minimize the sum of squared errors for each series over the period 1961-2099.

The second comparison is on the relative change between the maximum daily precipitation value over 50 years for the past (1961-2010) and the future (2050-2099). Formally, let

$Y_{45 \mathrm{~km}, P}=\max _{t \in\{1961, \ldots, 2010\}}\left(Y_{45 \mathrm{~km}, t}\right)$

and

$Y_{45 \mathrm{~km}, F}=\max _{t \in\{2050, \ldots, 2099\}}\left(Y_{45 \mathrm{~km}, t}\right)$ be the raw simulated maximum daily precipitation over 50 years for the past and the future, respectively. The relative change $\Delta_{45 \mathrm{~km}}$ for the raw simulation is given by

$\Delta_{45 \mathrm{~km}}=100 \%\left(\frac{Y_{45 \mathrm{~km}, F}-Y_{45 \mathrm{~km}, P}}{Y_{45 \mathrm{~km}, P}}\right)$.

The values $Y_{4 \mathrm{~km}, P}^{(k)}$ and $Y_{4 \mathrm{~km}, F}^{(k)}$ are defined in the same manner to calculate the relative change $\Delta_{4 \mathrm{~km}}^{(k)}$ for each disaggregated series $k$. The comparison of the relative changes is interesting from a practical point of view. In many cases (e.g., design of water infrastructures), the aim is to evaluate whether the highest expected extreme over a given period of time will increase or not in the future.

\section{Analyses of the results}

\subsection{Validation of the simulations (1961-2000)}

In this subsection, we intend to distinguish the sources of errors accounted for in Eq. (6) (Sect. 4.1). Before doing so, however, Fig. 2 presents the relative differences between the raw simulated and observed distribution of daily precipitation from 1961 to 2000 (May to October), along with the mean difference (bias) for the whole period. It illustrates that despite the high positive overall bias for the three simulations (from 59 to $65 \%$ ); the more intense precipitation depths are sometimes underestimated (i.e., $Y_{45 \mathrm{~km}}-X<0$ for higher percentiles). The fact that the bias is strongly negatively correlated with the intensity of precipitation suggests that the difference between the spatial resolution of the observed and simulated data has a substantial impact on the daily bias. In all likelihood, the relatively good agreement between observed and simulated high intensity daily precipitation occurs because the positive bias of the simulations is counterbalanced by the negative bias induced by the bulk spatial resolution of the CRCM grid node.

Figure 3 shows the difference between the $45 \mathrm{~km}$ CRCM tile and the mean 12,8 and $4 \mathrm{~km}$ disaggregated pixels AMDPs. The impact of disaggregation seems to increase with the intensity (return period) and to decrease with the pixel size, but the variability prevents the exact appraisal of both effects. For the maximum value of daily precipitation over 40 years (May to October, 1961-2000), the differences between the raw simulations and the mean $12 \mathrm{~km}$ disaggregated pixel $\left(Y_{45 \mathrm{~km}}-Y_{12 \mathrm{~km}}^{*}\right)$ vary between -13 and $-23 \mathrm{~mm}$ (disaggregated values higher than raw values) for the three simulations. For the 8 and the $4 \mathrm{~km}$ disaggregated pixels, the differences $\left(Y_{45 \mathrm{~km}}-Y_{8 \mathrm{~km}}^{*}\right)$ and $\left(Y_{45 \mathrm{~km}}-Y_{4 \mathrm{~km}}^{*}\right)$ vary between -16 and $-28 \mathrm{~mm}$ and -22 and $-38 \mathrm{~mm}$, respectively. These results suggest that if the disaggregation model was calibrated and applied at a finer resolution (i.e., finer pixels), the impact would have been greater, but it cannot be quantified with precision. 
Table 1. Estimation of the sources of errors (Eq. 6) for the highest daily precipitation value in the entire 1961-2000 period (May to October only). In parentheses, the values are expressed as the percentage of the half distance between the 5 th and the 95 th percentiles of the $4 \mathrm{~km}$ disaggregated data.

\begin{tabular}{lrrr}
\hline $\begin{array}{l}\text { Simulation } \\
\text { term }\end{array}$ & afx & \multicolumn{1}{c}{ agr } & \multicolumn{1}{c}{ aha } \\
\hline$\left(Y_{45 \mathrm{~km}}-X\right)$ & $-13.4 \mathrm{~mm}(-66.5 \%)$ & $-3.6 \mathrm{~mm}(-12.0 \%)$ & $32.2 \mathrm{~mm}(73.9 \%)$ \\
$\left(Y_{45 \mathrm{~km}}-Y_{4 \mathrm{~km}}^{*}\right)$ & $-26.0 \mathrm{~mm}(-129.1 \%)$ & $-38.2 \mathrm{~mm}(-126.4 \%)$ & $-22.2 \mathrm{~mm}(-51.0 \%)$ \\
$\left(Y_{4 \mathrm{~km}}^{*}-X\right)$ & $12.6 \mathrm{~mm}(62.6 \%)$ & $34.6 \mathrm{~mm}(114.4 \%)$ & $54.4 \mathrm{~mm}(124.9 \%)$ \\
\hline
\end{tabular}

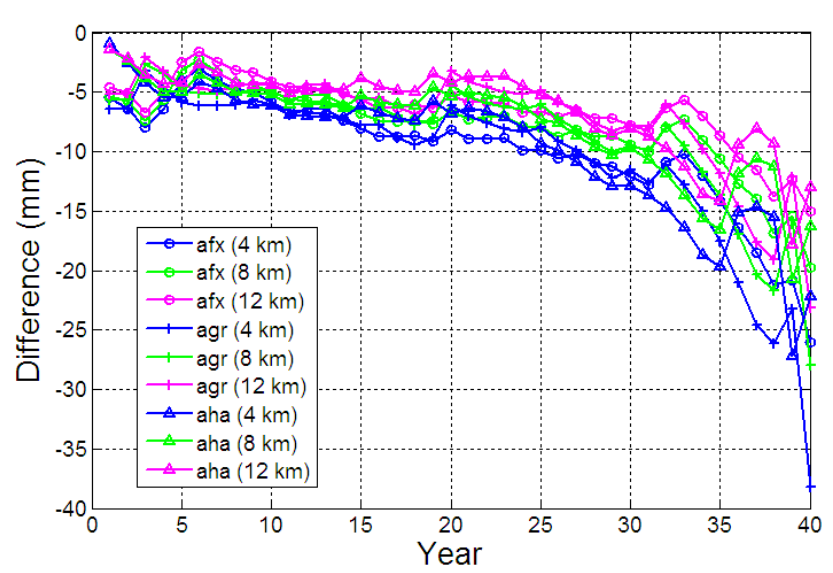

Fig. 3. Difference $(\mathrm{mm})$ between raw and mean disaggregated (at 12, 8 and $4 \mathrm{~km}$ ) AMDPs for the three simulations during the reference period (May to October, 1961-2000). Data are sorted out according to the magnitude of the annual maximum value (year $1=$ year with the smallest annual maximum value; year $40=$ year with the highest annual maximum value).

Figure 4 illustrates AMDPs (May to October, 1961-2000) extracted from the observations, the raw climate simulations and the 5th, 50th and 95th percentiles of the disaggregated series. The uncertainty band of disaggregation (difference between the 5 th and the 95 th percentile) increases with intensity (return period), which is expected. The overall fit, between the raw simulated and the observed curves, is good for simulations af $x$ and agr. However, as stipulated above, this good fit is the effect of a negative bias caused by the difference in spatial resolution and, in all likelihood, a positive bias caused by the physics of the simulations.

In order to identify the bias of the climate simulations for the most extreme events, Table 1 summarizes for each simulation the values of the terms of Eq. (6) for the highest daily precipitation over the entire 1961-2000 period. It shows that the impact of the disaggregation $\left(Y_{45 \mathrm{~km}}-Y_{4 \mathrm{~km}}^{*}\right)$ is significant for simulations $a f x$ and $a g r$. It also shows that the term $\left(Y_{4 \mathrm{~km}}^{*}-X\right)$ containing the bias of the CRCM simulation, the bias of the disaggregation model and the effect of the resolution difference between the $4 \mathrm{~km}$ pixel and the observation is positive for all simulations $(12.1,31.2$ and $47.2 \mathrm{~mm}$ for $a f x$, $a g r$, and $a h a$, respectively).

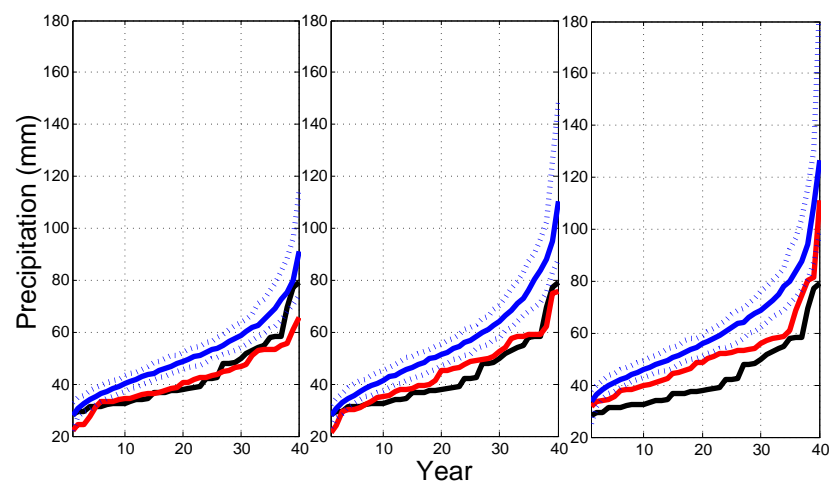

Fig. 4. Observed (black line), raw simulated (red line), and disaggregated (blue solid line: median; blue dotted lines: 5th and 95th percentile) AMDPs for simulations afx (left panel), agr (middle panel) and aha (right panel). The series are sorted in ascending order.

The estimation of the CRCM simulation bias, which is the purpose of the validation exercise, cannot be made with precision since the two other factors contained in the term $\left(Y_{4 \mathrm{~km}}^{*}-X\right)$, that is the bias of the disaggregation model and the difference in resolution between the $4 \mathrm{~km}$ pixel and the observations, are not known with exactitude. That being said, it is possible to get rough estimations of the impacts of both disaggregation model bias and the difference in resolution between the $4 \mathrm{~km}$ pixel and the observations. The results in Gagnon (2012) suggest that $4 \mathrm{~km}$ precipitation depths generated from the disaggregation model are more likely underestimated than overestimated for the most intense events. Also, Fig. 3 suggests that precipitation depths increase as the pixel size decreases (in other words with increasing resolution), implying that the impact of the difference in resolution between the $4 \mathrm{~km}$ pixel and the observations should be negative as well. It implies that the value of $\left(Y_{4 \mathrm{~km}}^{*}-X\right)$ should be a lower bound for the positive bias of the CRCM simulation. For the present case, it implies that the bias of the CRCM simulation for the AMDP in the 1961-2000 period (May to October) is at least as high as the difference between the disaggregated distribution and the observation series in Fig. 4. As most 5th percentile disaggregated values are greater than observed values, it can be said in these cases that the bias is positive with a significance level at least as high as $90 \%$ 


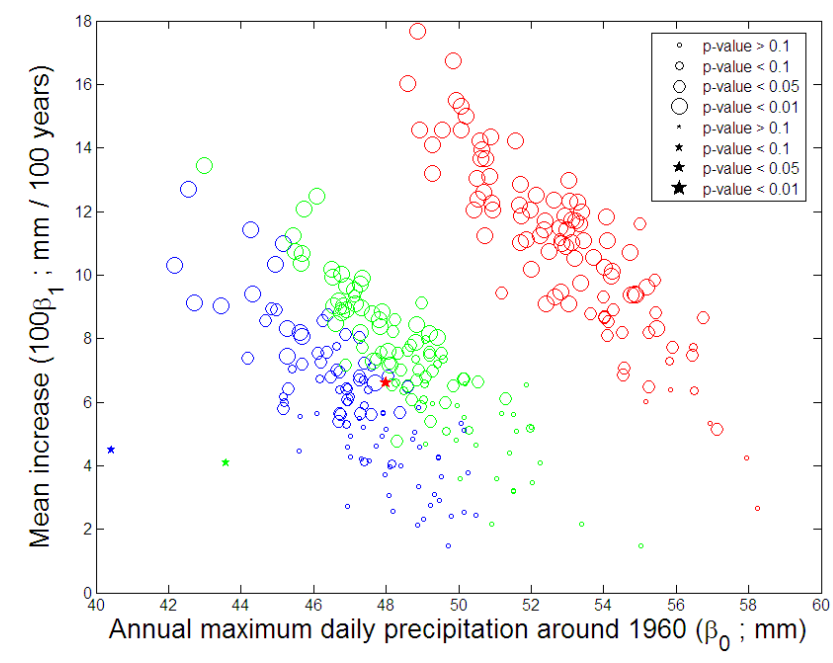

Fig. 5. Intercept $\left(\beta_{0}\right)$ and slope $\left(\beta_{1}\right)$ of the linear regression of the AMDP on the year for the 1961-2099 period for the disaggregated series (circles) and the raw simulations (stars) for $a f x$ (blue), agr (green) and aha (red). The size of the symbols increases with the level of significance of the trend (from the Mann-Kendall test).

(maybe more). Notable exceptions are the three highest maximum annual daily values for $a f x$ and the smaller maximum annual values for the three simulations. The most biased simulation is $a h a$; even the raw simulated annual maximums are higher than the observed maximums.

\subsection{Impact of climate change (1961-2099)}

Figure 5 shows the intercept $\left(\beta_{0}\right)$ and the slope $\left(\beta_{1}\right)$ of the linear regression of the AMDP on the year over the 1961-2099 period for the disaggregated series and the raw simulations. The maximum daily precipitation depths for 1960 estimated from the linear regression are 40.4, 43.6 and $48.0 \mathrm{~mm}$ for raw simulations afx, agr and aha, respectively. The 1960 maximum daily precipitation depths estimated in the same manner from the disaggregated values over the Choinière watershed are about 2 to $10 \mathrm{~mm}$ higher.

The mean increases over 100 years estimated from the linear regression are 4.5, 4.1 and $6.6 \mathrm{~mm}$ for raw simulations afx, agr and aha, respectively. The corresponding increases for each simulation are 11.1, 9.4 and $13.8 \%$ of the maximum annual estimated for 1960 . The increase is statistically significant at the $90 \%$ level for the three raw simulations according to the Mann-Kendall test.

The mean increases for the disaggregated series are generally higher. Over 100 years, the median of the disaggregated increases are 5.8, 7.3 and $11.1 \mathrm{~mm}$ for simulations afx, agr and $a h a$, respectively. Relative to the median disaggregated daily maximum estimated for 1960, these increases are 12.3, 14.9 and $20.8 \%$, respectively. The trends of most disaggregated series are significant at the $90 \%$ level according to the Mann-Kendall test.

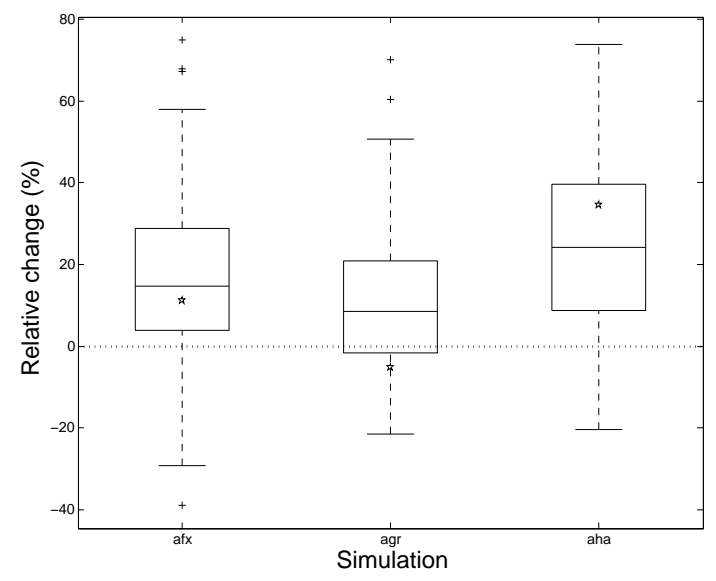

Fig. 6. Boxplot of the relative change (\%) in the highest daily precipitation between the future (2050-2099) and recent past periods (1961-2010) for the 100 disaggregated series of each simulation. The stars are the relative change for the raw simulations.

The higher increases for the disaggregated series are in all likelihood due to the variable CAPE. CAPE is accounted for in the standard deviation equation (Eq. 4) of the disaggregation model (Sect. 3). The Mann-Kendall test applied on the mean daily CAPE value of the AMDPs indicates that CAPE significantly increases for most series, raw and disaggregated. It means that extreme precipitation intensities come from more convective events in the future. Convective events produce more intense local precipitation than largescale events. For a given convective event, the local maximum may or may not fall on the watershed, but over several events, some local maximum will fall on the watershed and may produce higher annual maximum.

Figure 6 illustrates the relative difference between the highest daily precipitation for the past (1961-2010) and future (2050-2099) for each raw and disaggregated series. Both periods contain 50 years to ensure a fair comparison. It shows that the maximum is higher for the future than it is for the past for most series, but not for all cases. In fact, for the raw agr simulation, the maximum decreases. For the disaggregated series, 23, 29 and $12 \%$ of the series of simulations afx, $a g r$ and $a h a$ have negative relative changes, respectively. It highlights the fact that for the most extreme events, the natural climate variability is very important and can hide the CC signal.

To evaluate whether the disaggregation modifies significantly the relative change of the raw simulations, we calculated the percentage of disaggregated series for which the relative change is higher than the relative change of the raw simulation. If this percentage is large, say larger than $90 \%$, the relative change induced by the disaggregation will be considered significant. The results indicate that the relative change is higher than for the raw simulations for 58,84 and $33 \%$ of the disaggregated series of $a f x, a g r$ and $a h a$, respectively. It 
indicates that the disaggregation may have an impact in the evaluation of the CC signal, but it is not significant for the most extreme daily values of the three simulations.

\section{Conclusions}

In this work, a stochastic disaggregation model (Gagnon, 2012) was used as a tool to validate annual maximum daily precipitation (AMDP) for a reference period (May to October, 1961-2000) and to evaluate the impact of CC on a small watershed (Choinière watershed, sub-watershed of the Yamaska River, province of Québec, Canada). Three simulations coming from the same RCM (CRCM version 4.2.3) were analyzed.

The validation results indicate that disaggregation has a significant impact for most AMDP events (Fig. 4). Nevertheless, the disaggregation model did not permit the precise evaluation of the simulation bias (caused by a misrepresentation of the physical processes) for daily extreme because of two main factors.

First, even if the disaggregation model refines the spatial resolution from 45 to $4 \mathrm{~km}$, the gap between $4 \mathrm{~km}$ and the resolution of the observations might have a non-negligible impact on the validation results. To apply the disaggregation model at a finer scale, one needs to estimate the model parameters at the target scale first. This can be done for example with radar composite data as performed in Gagnon et al. (2012, 2013). However, if the observed data come from rain gauges, there will always be a gap between the resolution of the radar and the rain gauge data.

The second factor is the bias of the disaggregation model for the most convective events (Gagnon, 2012). Although the model already accounts for this type of event, more work needs to be done to better understand the role of CAPE on the spatial distribution of the precipitation at the local scale.

Despite these two limitations, the disaggregation model provided a way to illustrate that the AMDPs were significantly positively biased for most years for the three simulations, and in particular for the maximum over 40 years for simulations agr and aha (Table 1, Fig. 4).

For the CC evaluation, the results indicate that AMDPs tend to increase for both raw simulated and disaggregated series (Fig. 5). For the comparison of the maximum daily precipitation over 50 years between the past (1961-2010) and the future (2050-2099), the CC signal is slightly stronger for the disaggregated series compared to the raw simulation, but not significantly. It would be interesting to test whether an enhanced version of the disaggregation model, with a better representation of the role of CAPE, would increase the impact of the CC signal at local scale.

Despite the fact that the disaggregation does not significantly change the $\mathrm{CC}$ signal, disaggregation provides valuable information. In this work, each day was disaggregated 100 times, allowing for the calculation of confidence intervals for each simulation. It is noteworthy considering the small amount of extreme event data and their high variability. From a practical point of view, the ensemble of disaggregated series could be used to estimate an exceedance probability for a given future horizon.

Climate models are continuously improving their physical representation and their spatial resolution. For example, the CRCM now runs at a $15 \mathrm{~km}$ horizontal resolution. Nonetheless, stochastic disaggregation models will remain relevant since it produces a distribution of results for a unique event, and there will always be a need for high-resolution rainfall estimates.

To sum up, the difference in spatial resolution between climate models and the area of interest must be accounted for when investigating extreme precipitation events over a small area. For validation purposes, this difference in spatial resolution represents an important source of errors and might be more important than the bias of the climate models. For CC projections, it is one source of uncertainty among others and should be considered as well as uncertainty of climate models, size of the domain (when RCM are used), GHG emission scenarios, etc. While the disaggregation model used in this work could be improved, this study has illustrated that it could be a valuable tool to conduct an impact assessment study. In addition to the fact that the model preserves the spatial structure of the field, one advantage is that parameterization is related to physical properties of the events (CAPE, wind speed and wind direction). It allows the model to be more robust to $\mathrm{CC}$ or to applications in non-calibrated areas.

Acknowledgements. The CRCM data has been generated and supplied by Ouranos. Observed meteorological grid was provided by the CEHQ. Financial support for this work was provided by the second author's NSERC (Natural Sciences and Engineering Research Council of Canada) Discovery and Collaborative Research and Development grants (industrial partner: Ouranos/HydroQuébec). The authors also wish to thank Sébastien Tremblay and Stéphane Savary (INRS-ETE) for their technical support.

Edited by: A. A. Carsteanu

\section{References}

Amengual, A., Homar, V., Romero, R., Alonso, S., and Ramis, C.: Projections of the climate potential for tourism at local scales: Application to Platja de Palma, Spain, Int. J. Climatol., 32, 20952107, 2012.

Boé, J., Terray, L., Habets, F., and Martin, E.: Statistical and dynamical downscaling of the Seine basin climate for hydrometeorological studies, Int. J. Climatol., 27, 1643-1655, 2007.

Caya, D. and Laprise, R.: A Semi-Implicit Semi-Lagrangian Regional Climate Model: The Canadian RCM, Mon. Weather Rev., 127, 341-362, 1999. 
CEHQ - Centre d'expertise hydrique du Québec: Mise en place d'une plateforme de modélisation hydrologique à l'échelle du Québec méridional, Rapport interne au Centre d'expertise hydrique du Québec (CEHQ), Québec city, PQ, Canada, 25 pp. and appendices, 2012.

de Elía, R. and Côté, H.: Climate and climate change sensitivity to model configuration in the Canadian RCM over North America, Meteorol. Z., 19, 325-339, 2010.

Flato, G. M. and Boer, G. J.: Warming Asymmetry in Climate Change Simulations, Geophys. Res. Lett., 28, 195-198, 2001.

Flato, G. M., Boer, G. J., Lee, W. G., McFarlane, N. A., Ramsden, D., Reader, M. C., and Weaver, A. J.: The Canadian Centre for Climate Modeling and Analysis Global Coupled Model and its Climate, Clim. Dynam., 16, 451-467, 2000.

Fortin, V., Therrien, C., and Anctil, F.: Correcting wind-induced bias in solid precipitation measurements in case of limited and uncertain data, Hydrol. Process., 22, 3393-3402, 2008.

Fowler, H. J. and Ekström, M.: Multi-model ensemble estimates of climate change impacts on UK seasonal precipitation extremes, Int. J. Climatol., 29, 385-416, 2009.

Gagnon, P.: Désagrégation statistique de la précipitation mésoéchelle, Ph. D. thesis, Institut National de la Recherche Scientifique, Centre eau, terre et environnement, Université du Québec, Québec city, PQ, Canada, 245 pp., 2012.

Gagnon, P., Rousseau, A. N., Mailhot, A., and Caya, D.: Spatial Disaggregation of Mean Areal Rainfall using Gibbs Sampling, J. Hydrometeorol., 13, 324-337, 2012.

Gagnon, P., Rousseau, A. N., Mailhot, A., and Caya. D.: A Gibbs sampling disaggregation model for orographic precipitation, Int. J. Appl. Earth Observ. Geoinf., 22, 16-26, 2013.

Geman, S. and Geman, D.: Stochastic relaxation, Gibbs distribution and the Bayesian restoration of images, IEEE T. Pattern Anal. Mach. Intell., 6, 721-741, 1984.

Goodison, B. E., Louie, P. Y. T., and Yang, D.: WMO solid precipitation measurement intercomparison: Instruments and observing methods, Report No. 67, World Meteorological Organisation, Geneva, 1998.

Hanel, M. and Buishand, T. A.: Multi-model analysis of RCM simulated 1-day to 30-day seasonal precipitation extremes in the Czech Republic, J. Hydrol., 412-413, 141-150, 2012.

Harris, D. and Foufoula-Georgiou, E.: Subgrid variability and stochastic downscaling of modeled clouds: Effects on radiative transfer computations for rainfall retrieval, J. Geophys. Res., 106, 10349-10362, 2001.

IPCC.: Climate Change 2007: The Physical Science Basis, Contribution of Working Group I to the IPCC Fourth Assessment Report, Cambridge University Press, Cambridge, UK, 996 pp., 2007.

Jungclaus, J. H., Botzet, M., Haak, H., Keenlyside, N., Luo, J.J., Latif, M., Marotzke, J., Mikolajewicz, U., and Roeckner, E.: Ocean circulation and tropical variability in the AOGCM ECHAM5/MPI-OM, J. Climate, 19, 3952-3972, 2006.

Kendall, M. G.: Rank Correlation Methods, Griffin, London, 1975.

Lin, Y. and Mitchell, K. E.: The NCEP Stage II/IV hourly precipitation analyses: development and applications, Preprints, $\mathrm{Pa}$ per 1.2, 19th Conf. on Hydrology, 9-13 January 2005, American Meteorological Society, San Diego, CA, 2005.
Lovejoy, S. and Schertzer, D.: On the simulation of continuous in scale universal multifractals, part I: Spatially continuous processes, Comput. Geosci., 36, 1393-1403, 2010.

Mackay, N. G., Chandler, R. E., Onof, C., and Wheater, H. S.: Disaggregation of spatial rainfall fields for hydrological modelling, Hydrol. Earth Syst. Sci., 5, 165-173, doi:10.5194/hess-5-1652001, 2001.

Mann, H. B.: Nonparametric tests against trend, Econometrica, 13, 245-259, 1945.

Mladjic, B., Sushama, L., Khaliq, M. N., Laprise, R., Caya, D., and Roy, R.: Canadian RCM projected changes to extreme precipitation characteristics over Canada, J. Climate, 24, 2565-2584, 2011.

Nakicenovic, N. and Swart, R.: Special Report on Emissions Scenarios, A Special Report of Working Group III of the Intergovernmental Panel on Climate Change, Cambridge University Press, Cambridge, UK and New York, NY, USA, 599 pp., 2000.

Over, T. M. and Gupta, V. K.: A space-time theory of mesoscale rainfall using random cascades, J. Geophys. Res., 101, 2631926331, 1996.

Paquin, D.: Évaluation du MRCC4 en passé récent (1961-1999), Rapport interne No. 15,Équipe Simulations climatiques, Ouranos, 2010.

Perica, S. and Foufoula-Georgiou, E.: Model for multiscale disaggregation of spatial rainfall based on coupling meteorological and scaling descriptions, J. Geophys. Res., 101, 26347-26361, 1996.

Roberts, G. O. and Smith, A. F. M.: Simple conditions for the convergence of the Gibbs sampler and Metropolis-Hastings algorithms, Stoch. Process. Appl., 49, 207-216, 1994.

Rousseau, A. N., Gagnon, P., Savary, S., Freudiger, D., and Klein, I.: Intégration de l'impact des changements climatiques (CC) dans la détermination des crues maximales probables (CMP) afin d'appuyer les usagers dans l'évaluation de la sécurité des barrages, Final report No. R-1385 presented to Ouranos Consortium, Québec city, PQ, Canada, 286 pp., 2012.

Scinocca, J. F., McFarlane, N. A., Lazare, M., Li, J., and Plummer, D.: Technical Note: The CCCma third generation AGCM and its extension into the middle atmosphere, Atmos. Chem. Phys., 8, 7055-7074, doi:10.5194/acp-8-7055-2008, 2008.

Sharma, D., Das Gupta, A., and Babel, M. S.: Spatial disaggregation of bias-corrected GCM precipitation for improved hydrologic simulation: Ping River Basin, Thailand, Hydrol. Earth Syst. Sci., 11, 1373-1390, doi:10.5194/hess-11-1373-2007, 2007.

Sunyer, M. A., Madsen, H., and Ang, P. H.: A comparison of different regional climate models and statistical downscaling methods for extreme rainfall estimation under climate change, Atmos. Res., 103, 119-128, 2012.

Yang, D., Goodison, B. E., Metcalfe, J. R., Louie, P. Y. T., Leavesley, G., Emerson, D., Hanson, C. L., Golubev, V. S., Elomaa, E., Gunther, T., Pangburn, T., Kang, E., and Milkovic, J.: Quantification of precipitation measurement discontinuity induced by wind shields on national gauges, Water Resour. Res., 35, 491508, 1999.

Yu, Z., Barron, E. J., Yarnal, B., Lakhtakia, M. N., White, R. A., Pollard, D., and Miller, D. A.: Evaluation of basin-scale hydrologic response to a multi-storm simulation, J. Hydrol., 257, 212-225, 2002. 